\title{
Efek model kids' athletics memberikan nilai tambah dalam meningkatkan konsep diri siswa
}

\section{The impact of kids' athletics model on improving students' self- concepts}

\author{
Rifki Nanda Putra $^{1} \&$ Bafirman $^{2}$ \\ 1Postgraduate Program, Universitas Negeri Padang, Jl. Prof. Dr. Hamka Padang, West \\ Sumatera Province, 25171, Indonesia
}

Received: 31 August 2019; Revised: 13 November 2019; Accepted: 13 March 2020

\begin{abstract}
Abstrak
Tujuan penelitian ini adalah untuk menguji keefektifan model kids' athletics untuk meningkatkan konsep diri siswa. Penelitian ini adalah pre-experimental design dengan rancangan one group pre-test post test design. Subjek dalam penelitian ini melibatkan 20 siswa Sekolah Dasar. Instrumen yang digunakan berupa kuesioner konsep diri dengan menggunakan skala nominal. Analisis yang digunakan untuk menguji keefektifan konsep diri sebelum dan sesudah diberikan perlakuan model kids' athletics adalah uji jenjang bertanda Wilcoxon. Hasil penelitian menunjukkan bahwa terdapat kenaikan hasil konsep diri siswa setelah diberikan perlakuan berupa model kids' athletics. Dapat simpulkan bahwa model kids' athletics efektif untuk meningkatkan konsep diri siswa.
\end{abstract}

Kata kunci: keefektifan, kids' athletics, konsep diri, model pembelajaran.

\begin{abstract}
The objective of this study is to test the effectiveness of kids' athletics learning model in cultivating students' self-concepts. This research is a pre-experimental design with one group pretest-posttest design. The subjects in this research are 20 elementary school students. Furthermore, the applied instrument is a selfconcept questionnaire with a nominal scale. The Wilcoxon signed-rank test is employed to test the effectiveness of self-concepts before and after the kids' athletics treatment. Henceforth, the results show the increase of students' selfconcepts after being treated of kids' athletics models. To sum up, the kids' athletics model is effective for improving students' self-concepts.
\end{abstract}

Keywords: effectiveness, kids' athletics, learning model, self-concepts.

\section{PENDAHULUAN}

Pendidikan Jasmani, Olahraga dan Kesehatan (PJOK) harus dimulai dari anak-anak untuk membentuk pertumbuhan organik, motorik, intelektual dan perkembangan emosional (Paramitha \& Anggara, 2018). PJOK memberikan peluang pada siswa untuk terlibat langsung dalam beraneka pengalaman belajar melalui aktivitas gerak yang dilakukan secara terstruktur, tertuju dan terencana. Pendidikan saat ini mengusulkan 
model pendidikan berfokus tidak hanya pada pengembangan kemampuan kognitif siswa tetapi juga keterampilan emosional mereka. Rosdiani (2012) mengemukakan bahwa PJOK adalah media atau perantara untuk mendorong perkembangan keterampilan motorik, kemampuan fisik, pengetahuan, penalaran dan penghayatan nilai-nilai (sikap, mental, emosional, sosial). Oleh karena itu pendidikan anak melalui gerak dasar perlu menyediakan berbagai kegiatan yang dapat mengembangkan berbagai aspek perkembangan potensi atau kemampuan anak.

Perkembangan potensi yang dimiliki seseorang tidak akan terwujud begitu saja apabila tidak diupayakan. Menurut Astuti (2015) upaya seseorang untuk mengaktualisasikan potensinya akan membentuk sikap dan kepribadian. Yang terpenting ialah bahwa aktualisasi potensi dapat diperoleh apabila seseorang memiliki konsep diri. Konsep diri merupakan dasar bagian anak untuk memutuskan apakah ia akan membenci dirinya sendiri atau akan mencintai dirinya sendiri (Murdoko, 2006). Pendapat lain dari LaRossan \& Reitzes dalam buku West (2008) yaitu individu-individu mengembangkan konsep diri melalui interaksi dengan orang lain dan konsep diri membentuk motif yang penting untuk perilaku. Konsep diri dikatakan berperan dalam menentukan perilaku karena konsep diri menentukan pengharapan individu.

Konsep diri merupakan pondasi utama keberhasilan proses pembelajaran, termasuk bagaimana seseorang belajar meningkatkan kecerdasan emosionalnya. Sejalan dengan pendapat Brooks dalam Masturah (2017) konsep diri sebagai gambaran terhadap diri individu sendiri, baik itu yang bersifat fisik, sosial dan psikologis yang diperoleh melalui pengalaman dari interaksi antara individu dengan orang lain. Jadi konsep diri mencakup berbagai aspek perkembangan pada diri seseorang, termasuk aspek kognitif, sosial, maupun emosional. Salah satu dari proses ini adalah fenomena harga diri seorang anak mengembangkan persepsi diri dan nilai-nilai yang ia yakini sebagai nilai di masyarakat (Sirgy, 2015). 
Dari hasil penelitian Widiarti (2017) menunjukkan bahwa: 1) konsep diri siswa berimbang antara yang memiliki konsep diri rendah, dengan yang memiliki konsep diri tinggi; 2) dari segi aspek-aspek konsep diri, memperoleh hasil: (a) kerja/akademik yang tinggi ada 58,4\% (262 siswa), (b) keluarga yang tinggi ada 57,2\% (257 siswa), (c) fisik yang tinggi ada 55.7\% (250 siswa), (d) etika- moral yang rendah ada 49\% (220 siswa), (e) sosial yang rendah ada 49\% (220 siswa), dan (f) personal yang rendah ada 48,1\% (216 siswa); 3) konsep diri yang cenderung rendah ialah etikamoral, sosial, dan personal, maka digunakan pendekatan bagi pendamping.

Beberapa penelitian lain di eropa menunjukkan masalah orang tua sebagai penyebab utama harga diri positif atau negatif pada usia remaja awal. Corrigan (2004) berpendapat bahwa siswa yang menganggap diri mereka efesien dan kompeten berpartisipasi lebih banyak dikelas dari pada mereka yang tidak melihat dengan efesiensi yang sama. Menurutnya anak-anak dengan harga diri tinggi cendrung ekstrovert, percaya diri dalam mengambil resiko, sedangkan mereka yang memiliki harga diri yang rendah cendrung tertutup, pemalu, dan terbatas.

Hasil penelitian lain yang mencakup indikator konsep diri menunjukkan bahwa persepsi diri adalah suatu yang kompleks yang berasal dari reaksi orang tua, kerabat dan orang lain (Alipor, Hossein and Rahmani, 2012). Persepsi anak tentang diri mereka sendiri, anak-anak akan memperhatikan orang tua mereka dari segi perilaku dalam persepsi kepintaran dan kemampuan. Jika mereka tidak dapat melihat perilaku dalam diri orang tua mereka, harga diri mereka tidak dapat ditingkatkan (Badeleh, Fathi, \& Ostadi, 2013). Disamping itu, pesan-pesan yang diterima anak tentang orang-orang di sekitarnya dapat memengaruhi konsep diri mereka sendiri, anak-anak biasanya menganggap segala sesuatu sebagai kenyataan dan hal tersebut meningkatkan daya tarik mereka. Dari indikator konsep diri yaitu harga diri orang tua juga memengaruhi anak mereka. Seharusnya orang tua selalu ingat bahwa kegiatan yang mereka lakukan lebih memengaruhi harga diri anak dari 
pada dirinya sendiri. Anak biasanya berperilaku sesuai dengan perilaku orang tua mereka. Karena itu, keluarga memainkan peran penting dalam membentuk harga diri anak. Hasil penelitian dari Ganji, Mahdi pada tahun 1999 dalam Leila et al. (2013) mengungkapkan bahwa anak dari orang tua yang bercerai memiliki harga diri sangat rendah. Harga diri ini merujuk pada tingkat dimana individu menganggap mereka mampu dan penting. Dengan kata lain, harga diri adalah pengalaman pribadi yang dapat diamati dalam perilaku individu. Jika orang mengevaluasi diri mereka secara positif, maka harga diri mereka akan ditingkatkan dan sebaliknya (Veenhoven, 2006).

Menyikapi permasalahan yang ada, maka perlu ditemukan model pembelajaran yang tepat untuk mengatasi permasalahan tentang rendahnya konsep diri tersebut. Salah satu model pembelajaran itu ialah melalui model kids' athletics, untuk meningkatkan konsep diri siswa sekolah dasar. Kids' athletics merupakan cabang olahraga yang diperlombakan pada tingkat O2SN (Olimpiade Olahraga Siswa Nasional) untuk tingkat sekolah dasar. Model pembelajaran kids' athletics ialah kegiatan fisik yang multirateral, pada prakteknya mereka akan melakukan berbagai aktivitas fisik (lari, lempar, lompat, dan rolling) yang diselaraskan dengan karakteristik tingkat umur anak. Selain itu model pembelajaran kids' athletics membuat anak-anak merasa gembira melalui bentuk-bentuk permainan dan perlombaan baru serta beragam gerakan. Perlombaan dari model kids' athletics mengharuskan sejumlah anak untuk turut berkontribusi melakukan aktivitas antar pos yang ada. Kids' athletics di rekomendasikan cocok dengan pembelajaran PJOK di sekolah dasar.

Proses pendidikan jasmani akan berhasil jika dengan metode dan model pembelajaran sesuai dengan kurikulum yang diterapkan dan karakteristik kemampuan yang ingin di capai. Artinya guru harus mengetahui kemampuan, kesenangan, kebutuhan anak akan gerak dan guru PJOK pada tingkat sekolah dasar harus bisa menyadari bahwa model pembelajaran yang tepat dan sesuai dengan pertumbuhan dan perkembangan dalam meningkatkan konsep diri siswa dan membantu 
siswa untuk menggunakan tubuhnya lebih efisien. Sehingga melalui peningkatan konsep diri di usahakan tercapainya profil individu manusia Indonesia yang siap secara intelektual, mental, fisik dan rohani untuk menyongsong masa depan.

\section{METODE}

Penelitian ini adalah penelitian pre-experimental design dengan bentuk rancangan menggunakan one group pre-test post-test design, sebab peneliti tidak menggunakan variabel kontrol dan sampel tidak dipilih secara acak sehingga hasil dari penelitian akan menunjukkan tingkat konsep diri siswa sebelum dan sesudah diberikan model pembelajaran kids' athletics. Subjek dalam penelitian ini adalah 20 siswa Sekolah Dasar Negeri 28 Rokan IV Koto, Kabupaten Rokan Hulu, Propinsi Riau yang memiliki tingkat konsep diri sedang berdasarkan pengukuran dengan instrumen kuesioner konsep diri dengan menggunakan skala nominal. Kuisioner konsep diri berdasarkan dari teori pembentukan konsep diri (Burns, 1979), yang terdiri dari 3 indikator, yaitu: (1) citra tubuh; (2) harga diri; dan (3) peran. Setelah diberikan model kids' athletics, dilakukan pengukuran kembali dengan menggunakan instrumen kuisioner konsep diri agar didapati apakah terdapat perbedaan hasil konsep diri sebelum dan sesudah diberikan pembelajaran model Kids' Athletics. Analisis kuantitatif menggunakan statistik non-parametric. Analisis yang dilakukan untuk menguji penelitian ini ialah uji jenjang bertanda Wilcoxon, dalam (Kadir, 2016). Uji statistik yang di lakukan dengan menggunakan SPSS 23.

\section{HASIL}

Analisis hasil uji efektifitas model kids' athletics untuk meningkatkan konsep diri siswa dapat dilihat dalam tabel 1 dan output penghitungan dapat dilihat pada tabel 2. 
Tabel 1. Hasil Uji Efektifitas Model Kids' Athletics

\begin{tabular}{cccccc}
\hline No & Objek & Sebelum & Kategori & Sesudah & Kategori \\
\hline 1 & Citra tubuh & 88 & Baik & 96 & Sangat baik \\
\hline 2 & Harga diri & 75 & Sedang & 96 & Sangat baik \\
\hline 3 & Peran & 83 & Baik & 100 & Sangat baik \\
\hline
\end{tabular}

Tabel 2. Rank Uji Jenjang Bertanda Wilcoxon

\begin{tabular}{|c|c|c|c|c|}
\hline & & $\mathbf{N}$ & Mean Rank & Sum of Ranks \\
\hline \multirow{4}{*}{$\begin{array}{l}\text { Sebelum - } \\
\text { Sesudah }\end{array}$} & $\begin{array}{l}\text { Negative } \\
\text { Ranks }\end{array}$ & $0^{\mathrm{a}}$ & 0.00 & 0.00 \\
\hline & Positive Ranks & $18^{\mathrm{b}}$ & 9.50 & 171.00 \\
\hline & Ties & $2^{c}$ & & \\
\hline & Total & 20 & & \\
\hline
\end{tabular}

\section{Keterangan:}
a. Post-test < Pre-test
b. Post-test $>$ Pre-test
c. Post-test $=$ Pre-test

Tabel 3. Hasil Statistik Uji Jenjang Bertanda Wilcoxon

\begin{tabular}{ll}
\hline & Test Statistics $^{\mathrm{a}}$ \\
\hline & Post test - Pree test $^{-3.736^{\mathrm{b}}}$ \\
\hline $\mathrm{Z}$ & .000 \\
\hline Asymp. Sig. (2-tailed) &
\end{tabular}

\section{Keterangan:}
a. Wilcoxon Signed Ranks Test
b. Based on negative ranks

Dari hasil tabel 2 diketahui bahwa negative ranks atau selisih (negatif) diperoleh nilai 0 baik pada N, Mean Rank, dan Sum of Rank. Hal ini bermakna tidak ada penurunan konsep diri antara sebelum dan sesudah diberikan pembelajaran berupa model kids' athletics. Selanjutnya, positive ranks atau selisih (positif) diperoleh nilai $\mathrm{N}=18$ yang artinya ke 18 siswa mengalami peningkatan konsep diri sebelum dan sesudah diberikan pembelajaran berupa model kids' athletics. Sedangkan Ties diperoleh nilai 2, yang bermakna terdapat subjek penelitian yang hasil tingkat konsep diri menetap antara sebelum dan sesudah diberikan perlakuan model kids' athletics. Dari tabel 2 juga didapati hasil bahwa hasil kenaikan rata-rata pada setiap subjek penelitian ada 9,5 poin. 
Hasil statistik uji jenjang bertanda Wilcoxon yang terdapat pada tabel 3 memperlihatkan bahwa nilai $Z$ hitung berjumlah -3,736, sedangkan nilai $Z$ tabel didapati dari tabel $Z$ dengan alpha $5 \%$ nilainya 0,0001 . Sedangkan pada nilai Asymp. Sig (2-tailed) diperoleh 0,000. Karena Z hitung $>Z$ tabel yaitu $-3,736>0,0001$ atau nilai sig 0,000 $<0,05$ selaras dengan pengujian statistik yang digunakan maka dapat disimpulkan bahwa terdapat kenaikan hasil konsep diri siswa antara sebelum dan sesudah diberikan pembelajaran berupa model kids' athletics.

\section{PEMBAHASAN}

Atletik merupakan salah satu mata pelajaran wajib di Sekolah Dasar (SD). Pengembangan kids' athletics merupakan suatu ide cemerlang agar anak-anak usia SD mengenal gerak dasar atletik sejak usia dini hingga sampai ke Universitas, bahkan menjadi seorang atlet. $\mathrm{Di}$ samping itu karakteristik dari pengembangan permainan atletik agar sewaktu pembelajaran atletik tidak membosankan dan oalahraga melelahkan sehingga berdampak pada tingkat percaya diri, konsep diri bahkan menggurangi dari tingkat kecemasan siswa SD.

Dalam sebuah penelitian yang dilakukan Aghdasi (2008) dan Sereshkeh \& Amirnejad (2013) yang membandingkan tingkat kecemasan dan konsep diri mahasiswa atletik dan non-atletik di Universitas Orumiye menggunakan konsep diri dan kuesioner self-assertiveness Charles Spielberg. Aghdasi memberitahu bahwa ada hubungan yang signifikan antara konsep diri siswa atletik dan non-atletik laki-laki dan bahkan perempuan non-atletik, ia juga menemukan hubungan yang signifikan antara konsep diri atlet wanita dan non-atlet pria. Dari hasil uji eksperimen lain memperlihatkan bahwa model kids' athletics dapat memberikan nilai tambah dalam meningkatkan konsep diri siswa. Sebagian dari harga diri seorang anak sangat dipengaruhi oleh gaya pegasuhan yang dialami seorang anak. (Cohen \& Lotan, 2014). Piaget dalam (Hergenhahn \& Olson, 2009) mengemukakan bahwa setiap pengalaman yang dialami oleh seseorang akan melibatkan asimilasi dan akomodasi, Keefektifan pembelajaran ditandai adanya hasil perolehan belajar yang dicapai siswa 
setelah terlibat dalam interaksi dengan sumber belajar. Istilah efektivitas menurut KBBI (2008) berarti sesuatu yang bersifat efektif yang berarti efek, akibat, pengaruh, kesannya. Jadi efektivitas artinya dampak, pengaruh, dan hasil yang ditimbulkan dari suatu tindakan dalam hal ini terhadap penggunaan model pembelajaran yang dikembangkan. Menurut Rusman (2012) keefektifan program pembelajaran ditandai dengan ciri-ciri yaitu: (a) berdasarkan teori pendidikan dan teori belajar dari para ahli , (b) mempunyai misi dan tujuan, (c) sebagai pedoman untuk perbaikan kegiatan siswa dikelas, (d) mempunyai urutan langkah-langkah pembelajaran (sintaks), adanya prinsip-prinsip reaksi, sistem sosial, dan sistem pendukung, (e) memiliki dampak sebagai akibat terapan model pembelajaran, dan (f) mempunyai rancangan pembelajaran dengan pedoman model pembelajaran yang dipilihnya. Aspek efektivitas dapat dilakukan apabila produk tersebut telah valid dan praktis. Efektivitas model pembelajaran yang dikembangkan dapat dilihat dari hasil belajar peserta didik pada ranah konsep diri.

Di Indonesia, ada pendapat yang menyatakan kids' athletics dianggap sebagai cabang olahraga pertandingan di tingkat 02SN (Olimpiade Olahraga Siswa Nasional) sekolah dasar. Lebih dari itu kids' athletics merupakan model pembelajaran yang melibatkan kegiatan fisik yang multirateral, pada pelaksanaannya siswa melakukan bermacammacam bentuk aktivitas fisik seperti lari, lempar, lompat, dan rolling yang diselaraskan dengan karakteristik tingkat umur siswa. Selain itu model pembelajaran kids' athletics memberikan kegembiraan kepada anak-anak. Pertandingan dari model kids' athletics memungkinkan sebagian besar anak untuk turut berpartisipasi melakukan aktivitas antar area pada model ini yang saling berdekatan. Sehingga kids' athletics di rekomendasikan cocok dengan pembelajaran pendidikan jasmani, olahraga dan kesehatan di sekolah dasar.

Petros et al. (2016) mengungkapkan bahwa model kids' athletics dapat memotivasi siswa sekolah dasar untuk belajar track and field, dalam hal yang sama juga dapat meningkatkan kebugaran jasmani. PJOK 
memberikan kesempatan pada anak untuk terlibat langsung dalam beraneka pengalaman dan PJOK membantu siswa untuk memperbaiki derajat kesehatan dan kebugaran jasmani melalui pemahaman, pengembangan sikap diri positif, dan keterampilan gerak dasar serta berbagai aktivitas jasmani. Studi khusus ini menunjukkan bahwa model kids' athletics yang efektif dapat diterapkan dalam pendidikan jasmani dengan sarana tambahan untuk meningkatkan kualitas pembelajaran mereka. Hasil ini tentunya menjadi riset yang menarik bagi para ahli, pendidik dan praktisi untuk mengimplementasikan model kids' athletics dalam proses pembelajaran, sehingga semua responden dapat terbantu dalam upaya meningkatkan konsep diri siswa.

\section{KESIMPULAN DAN SARAN}

Temuan penelitian menunjukkan bahwa model pembelajaran kids' athletics dapat meningkatkan tingkat konsep diri siswa. Keutamaan dari penelitian ini ialah penggunaan model dan strategi pembelajaran yang relatif baru, yaitu model pembelajaran kids' athletics berbasis permainan dalam meningkatkan konsep diri siswa. Melalui model pembelajaran kids' athletics, siswa berupaya mengembangkan sikap-sikap positif, motivasi untuk berprestasi, memiliki kepercayaan diri, rasa harga diri, dan sebagian siswa yang berolahraga memiliki konsep diri segi fisik dan emosional yang lebih baik dari pada mereka yang tidak. Dari berbagai keutamaan yang telah disebutkan, penelitian ini menyarankan model kids' athletics sudah semestinya bisa di implementasikan dalam proses pembelajaran yang merujuk dari bentuk-bentuk permainan dalam upaya meningkatkan konsep diri.

\section{REFERENSI}

Aghdasi MT, A. A. (2008). Comparing Anxiety and Self-concept Rate of Athletic and non-athletic Students of Orumiye University. Islamic Azad University-Sport Research Center, Tehran Islamic Azad University, Proceeding in Farsi.

Alipor, Hossein and Rahmani, N. (2012). A comparative study of Selfsteem in War Victims' and Non-war Victims' children. May, 16(4), pp:29-43.( In Persian). 
Astuti, R. D. (2015). Identifikasi faktor-faktor yang memengaruhi konsep diri siswa Sekolah Dasar Negeri Mendungan I Yogyakarta. Basic Education, 4(2).

Badeleh, M., Fathi, M., Aghamohammadian Sharbaf, H. R., Taghi Badeleh, M., \& Ostadi, N. (2013). Compare the effect of group cognitive behavioral hypnotherapy and group cognitive behavioral therapy on increasing the self-esteem of adolescents. Journal of Fundamentals of Mental Health, 15(59), 194-204.

Burns, R. B. (1979). The Self Concept: Theory, Measurement, Development and Behavior. Longman Group Limited.

Cohen, E. G., \& Lotan, R. A. (2014). Designing groupwork: strategies for the heterogeneous classroom third edition. Teachers College Press.

Corrigan, P. (2004). How stigma interferes with mental health care. American Psychologist, 59(7), 614-625. https://doi.org/10.1037/0003-066X.59.7.614

Hergenhahn, B. R., \& Olson, M. H. (2009). No TitleTheories of learning = (Teori belajar) / B.R. Hergenhahn, Matthew H. Olson (7th ed.). Kencana Prenada Media Group.

Kadir. (2016). Statistika Terapan. Rajawali Pers.

KBBI. (2008). Kamus Besar Bahasa Indonesia (Vol. 66). Pusat Bahasa.

Leila, S., Ebrahim, M. S., Nahid, S., \& Azizollah, A. (2013). The Relationship between Children's Self-Esteem and Parents' Educational Level. International Journal of Academic Research in Progressive Education and Development, 2(3), 11-21. https://doi.org/10.6007/ijarped/v2-i3/3

Masturah, A. N. (2017). Gambaran Konsep Diri Mahasiswa Ditinjau dari Perspektif Budaya. Indigenous: Jurnal Ilmiah Psikologi, 2(2). https://doi.org/10.23917/indigenous.v2i2.4934

Murdoko, E. W. H. (2006). Personal Quality Managemen. PT Elax Media Komputindo.

Paramitha, S. T., \& Anggara, L. E. (2018). Revitalisasi pendidikan jasmani untuk anak usia dini melalui penerapan model bermain edukatif berbasis alam. Jurnal Pendidikan Jasmani dan Olahraga, 3(1), 4151.

Petros, B., Ploutarhos, S., Vasilios, B., Vasiliki, M., Konstantinos, T., Stamatia, P., \& Christos, H. (2016). The effect of IAAF Kids' Athletics on the physical fitness and motivation of elementary school students in track and field. Journal of Physical Education and Sport, 16(3), 883-896. https://doi.org/10.7752/jpes.2016.03139

Rosdiani, D. (2012). Model Pembelajaran Langsung Dalam Pendidikan Jasmani dan Kesehatan. Alfabeta. 
Rusman. (2012). Model-Model Pembelajaran Mengembangkan Profesionalisme Guru (edisi kedua)tle (Edisi Kedu). PT Raja Grafindo Persada.

Sereshkeh, S. K., \& Amirnejad, S. (2013). Comparing Self-esteem and Self-concept of Athletic and Non-Athletic Students and Finding a Relationship between these two Variables. Applied Science, 1(1), 19-22.

Sirgy, M. J. (2015). Self-image/product-image congruity and advertising strategy. In Proceedings of the 1982 Academy of Marketing Science (AMS) annual conference (pp. 129-133). Springer, Cham.

Veenhoven, R. (2006). THE FOUR QUALITIES OF LIFE Ordering concepts and measures of the good life. Journal of Intelligent and Robotic Systems: Theory and Applications, 22(3-4), pp 74-100.

West, R. \& L. H. T. (2008). Pengantar Teori Komunikasi Analisis dan Aplikasi ((Terj. Maria Natalia Damayanti \& Maer). (eds.)). Salemba Humanika.

Widiarti, P. W. (2017). Konsep Diri (Self Concept) dan Komunikasi Interpersonal dalam Pendampingan Pada Siswa SMP Se Kota $\begin{array}{lll}\text { Yogyakarta. Informasi, } & 435 .\end{array}$ https://doi.org/10.21831/informasi.v47i1.15035 